\title{
The International Regulation Of Maternity Leave: Leave Duration, Predictability, And Employer-Co-financed Maternity Pay
}

Dorothea Alewell, (Email: D.Alewell@wiwi.uni-jena.de), University of Jena, Germany Kerstin Pull, (Email: Pull_Kerstin@gsb.stanford.edu), Stanford Business School

\begin{abstract}
Provisions for maternity leave are common among industrialized countries, but their institutional design varies distinctly from country to country. In this paper we analyze the costs of maternity leave legislation in the US, Germany, Denmark and the UK by comparing the legal provisions on leave durations and on employer-co-financed maternity pay. We argue that the costs of re-organization in response to maternity leave will not simply increase with its duration, but will instead be hump-shaped displaying a maximum at medium-leave durations. More than its expected duration, however, the predictability of leave duration will influence the costs of re-organization. Employer co-financed maternity pay further adds to these costs. Following our theoretical analysis, we review the existing empirical literature on maternity leave: While existing surveys among employers and working mothers are in line with our theoretical considerations, the mixed evidence presented in the existing econometric studies concerning the effect of leave duration on female wages and labor force participation may result from having excluded the issue of predictability of leave duration as well as the question of co-financed maternity pay. We close with (tentative) conclusions for the design of maternity leave provisions, which are currently being discussed and revised in many countries around the world.
\end{abstract}

\section{Introduction: Maternity Leave Legislation in an International Perspective}

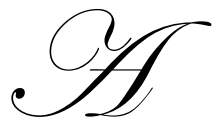

t present, almost every country has provisions for maternity leave allowing young mothers to leave their workplace for a limited time around childbirth and giving them the right to return to their job afterwards (ILO 1998). These provisions, however, vary distinctly from country to country: Whereas in the $U S$, maternity leave amounts to a maximum of 12 weeks of job-protected leave in a 12 months period, in Denmark a woman may leave her workplace for 18 weeks and then return to her previous job. In the $U K$, the latest changes in maternity leave regulations have increased the maximum duration of job-protected absence to 40 weeks. The right of re-instatement leaves the employer with the costs of having to temporarily reorganize work during maternity leave. Among others, these costs of re-organization will depend on the duration of leave, and at least partially they will be shifted on to the employees, in particular to young women that "carry the risk" of taking advantage of maternity leave provisions. As a result, maternity leave provisions intended to improve the labor market position of young women may in fact aggravate their situation. More than that, many countries also provide for maternity leave payments that are sometimes partially borne by the employer. While in the US maternity leave is unpaid, in Germany maternity pay reaches up to a $100 \%$ of the wage, the employer bearing approximately $40 \%$ of these costs (ALEWELL 2000). The costs of having to co-finance maternity pay add to the costs of reorganization and can be expected to further aggravate the labor market position of young women.

Readers with comment of questions are encouraged to contact the authors via e-mail.

Several papers have addressed the issue of maternity leave from an international perspective and have analyzed their effect on the labor market position of young women (see e.g. RUHM/TEAGUE 1997; RUHM 1998). However, these papers typically include a large number of countries and only briefly review the regulations in place. 
They typically concentrate on leave duration as a proxy for the costs of maternity leave imposed on the employer leaving aside other potentially important elements of the regulations such as employer co-financed maternity pay or the predictability of leave duration. In this paper, we will analyze both, the expected effect of leave duration and predictability as well as the effect of burdening the employer with costs of maternity pay on the labor market position of young women. Concerning leave duration, we argue - and here again we depart from the existing papers on maternity leave - that the costs of re-organization accruing to the employer will not steadily increase with the duration of maternity leave, but that we will instead observe a hump-shaped cost curve, where intermediate leave durations may well be the most costly for employers. Furthermore, we also highlight the importance of predictability concerning leave duration. After that, we present a detailed analysis of maternity leave regulations concerning the expected duration of leave, its predictability and employer co-financed maternity pay for 4 industrialized countries whose regulations may serve as examples for a wider class of stipulations in use: the US, Germany, Denmark and the $U K$. Next we revise the existing empirical studies on the effects of maternity leave provision in the light of our theoretical considerations. We close with (tentative) conclusions for the design of maternity leave provisions that are currently being discussed and revised in many countries around the world.

\section{The Costs of Maternity Leave Imposed on Employers: Theoretical Considerations}

Existing studies on the effect of maternity leave provisions on women's labor market position concentrate on the duration of maternity leave as a proxy for the costs accruing to employers - the underlying hypothesis being that the longer the leave duration, the more human capital is being lost. In many cases, however, the loss of human capital during a limited absence of several months may not be the main cost factor for employers faced with a mother on leave who wishes to return to her previous job. Moreover, it may well be the re-organization of work during absence and thereafter, that causes a problem to the employer. Consequently, in what follows we will focus on the costs of re-organization in response to maternity leave and how these are influenced by (a) the expected duration of leave and (b) by its predictability. After that we highlight the (much neglected) effect of making employers cofinance maternity pay on women's labor market position.

The fact that a woman may leave work for a longer period of time and that she has the right to return to her job afterwards, may cause severe organizational problems to her employer. Depending on the duration of leave, the employer may choose to employ a substitute or to arrange for work-sharing such that the remaining employees fulfill the tasks of the mother on leave. Some workplaces may also allow for leaving the work left undone until the employee returns, but this would seem to be only feasible when the duration of absence is rather short.

Having the work done by co-workers should also be regarded as a solution primarily to short-term leaves. The longer the leave, the more problematic it will generally be to find a satisfying and durable solution for shifting the work formerly done by the worker on leave to her co-workers. Heavier workloads for co-workers may in the long run lead to dissatisfaction and increased fluctuation, more error-prone work and lower productivity. Hence, we would expect the costs of work-sharing solutions borne by the employer to be a function of the duration of leave such that employer costs will generally increase with increasing maternity leave duration. Whether co-workers are qualified to take on some of the tasks of the woman on leave depends on the task distribution in the work groups. If the work formerly done by the woman on leave is of the same or of a similar kind as the work done by most of the co-workers, that is if task structures are more or less homogenous, the cost of arranging work-sharing solutions will be comparatively lower than if the task structures are heterogeneous. Thus, while the slope of the work-sharing cost function centrally depends on the duration of the leave, the absolute level of the cost function will be influenced by the homogeneity or heterogeneity of the task structures within firms and will vary between firms, hierarchical levels and work groups. It can further be conjectured that shifting the work to co-workers will be easier for larger firms were homogenous work-groups are more likely to be found.

The costs of employing a substitute, however, will generally decrease with increasing maternity leave duration, especially for skilled jobs: The higher the prerequisites on the skill level of the employee who could serve as a substitute, the more difficult it will be to find an adequate substitute for a short period of time. Recruiting substitutes gives rise to fixed costs, for example through advertising the job, selection processes and contract writing. The longer the duration of the employment of the substitute and thus the duration of maternity leave, the lower the recruiting 
cost per unit of employment time. Moreover, the substitute will have to get used to his or her work and full productivity will only be reached after some time. Thus, the slope of the substitution cost function is negative due to the effect of the duration of maternity leave. However, firm-specific human capital will play a major role for the level of substitution costs: If the amount of firm-specific knowledge needed in order to perform a certain job is significant, then a short term leave may not provide enough time for the substitute to acquire the skills needed or it may simply be too costly to train the substitute in the light of its short time horizon. Irrespective of the amount of general human capital needed in a certain job a short period of leave may in fact preclude the employment of a substitute as a result of the specific knowledge involved in performing job-related tasks and the costs of building these skills.

We consequently expect the following shape of the re-organization-cost curves (figure 1) where $C_{\text {sharing }}$ denotes the costs of finding a work-sharing arrangement with the recumbent workers and where $C_{\text {substitute }}$ denotes the costs of employing a substitute for the mother on leave. As an employer at least in principle has the choice between looking for a work-sharing agreement and employing a substitute (as for the latter, he might, however, be restricted by legal regulations on fixed-term employment), the costs of maternity leave re-organization that accrue to him are represented by $C=\min \left(C_{\text {sharing }}, C_{\text {substitute }}\right)$ representing the lower bound of $C_{\text {sharing }}$ and $C_{\text {substitute }}$ which gives the relevant re-organizing cost curve for employers.

\section{Figure 1: Costs of work-sharing and costs of employing a substitute}

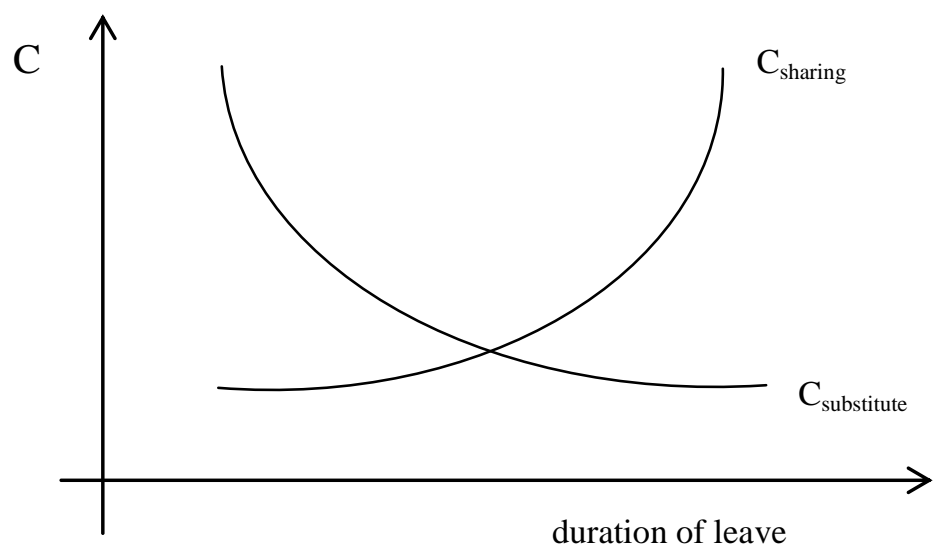

As a result, it may well be that intermediate levels of maternity leave are especially costly for the process of re-organization as they render work-sharing agreements more difficult while not yet allowing for practicable replacement solutions. The hypothesis implicit or explicit in most of the existing literature that longer durations of maternity leave lead to higher costs for the employers does not take into account the employer's re-organization problem and is solely built on the assumption that longer leave durations will be accompanied by a larger loss in human capital and work experience. For the vast majority of jobs and leave durations (in many countries they are between 12 and 16 weeks) the depreciation of human capital may, however, not be the biggest problem. Only for the very long leave periods (of 40 weeks e.g., as in the $U K$ ) as well as for mothers entering long-term parental leave (see below), the human capital argument would seem to be of relevance.

In addition to providing maternity leave durations of varying lengths the countries under consideration also show distinctive differences in how far they create uncertainty about the actual duration of the women's absence. In the literature it has been frequently argued that maternity leave does not cause any major problems to employers because of its predictability (see e.g. OECD 1995: 189): employers typically know well in advance that one of their employees will be on maternity leave in the near future. However, there is quite a difference between compulsory minimum durations of maternity leave and maximum durations in most countries, with the woman on leave often being the party who can decide whether to take maximum leave or not. Additionally, and more importantly, a young mother may decide not to return to work after maternity leave and either quit her job completely, or she may decide to take advantage of additional parental leave provisions offered in most countries. While parental leave typically concerns a long-term leave granted to either parent, in most countries it remains to be "a woman's affair" (BRUN- 
ING/PLANTENGa 1999: 204; for an empirical assessments of reasons see e.g. RosT 1999). The possibility to quit the job at the end of maternity leave or to benefit from parental leave provisions introduces an important source of uncertainty into the process of re-organization faced by the employer and may completely and unexpectedly alter his decision to either have the leave-taker's co-workers share the work left undone or to employ a substitute. As a consequence, even if the duration of maternity leave is more or less predictable in most countries, this is not generally true for the total duration of leave related to childbirth. Considering the predictability of total leave duration related to childbirth, we will broaden our analysis and include those aspects of parental leave stipulations that influence the predictability of total leave duration. But also the regulation of maternity leave itself can create uncertainty on its duration: the span between compulsory (minimum) and maximum leave duration may be large, notice periods may be short and veto-rights of the employer may be weak. The more uncertainty on leave duration is created, the larger the possible deviations from the optimal work-sharing or substitution arrangements that would have been chosen under certainty. Hence, uncertainty about leave durations will in general increase the costs of re-organization and may foster employers' reluctance to employ women in the relevant age groups at equal conditions as men. The lower the predictability of leave duration, the larger the expected aggravating effect on young women's labor market position.

In addition to the costs of re-organization, a further and potentially large cost factor of maternity leave regulations is represented by the payments a women receives while she is on leave. If employers have to bear some or all of the wage replacement costs during maternity leave, we can interpret this as an insurance of female employees by the employer against the risks of wage loss due to pregnancy and motherhood (JUNGWIRTH 1998, p. 82). Like any insurer, the employer will in general not offer insurance for free but will demand insurance premiums in exchange for his services. Explicit premium payments are excluded in all countries under consideration. However, implicit premium payments are feasible: employers may pass on maternity pay costs to the female employees in the relevant age groups via wage reductions (GRUBER 1994: 623). Besides representing costs of re-organization that are being passed on to female employees, wage differentials between men and women in the relevant age groups may therefore also be interpreted as implicit insurance premiums. The passing on of employer borne costs of maternity pay to female employees will, however, often not be complete. Legally or collectively set minimum wages may constitute lower bounds on wages and hamper wage reductions for women in lower income areas. Anti-discrimination rules or affirmative action programs with "equal pay for equal work" wage setting rules may have the same effect. If such instruments take effect and restrict the payment of implicit insurance premiums by female employees benefiting from maternity leave, the marginal costs of employing women will be higher than the marginal costs of employing men. This may result in a lower employment of women compared to the employment of men for each given wage: Like other insurers, the employer will try to influence the structure of the insured group and have as many "good risks" and as little "bad risks" as possible in his insured portfolio. As the maternity leave legislation in most countries explicitly bans layoffs of pregnant women and young mothers, the structure of the insured group cannot easily be changed by dismissals. Therefore, negative effects on the recruiting of female employees in the relevant age groups can be expected (MITCHELL 1990: 306, SUMMERS 1989: 181). If wage replacement costs borne by the employer are calculated as a percentage of women's wages, then the wage differential between women and men can further be expected to increase with the wage level.

So far we have argued that certain elements of maternity leave regulations cause problems or costs for employers and may ceteris paribus worsen the labor market situation of women. However, besides the direct wage and employment effects maternity leave regulations may have other, more indirect effects on the employment situation and wages of women: If the mandated benefit "paid maternity leave" (or even maternity leave in general) is valued positively by the women, their labor supply will rise, eventually decreasing wages. If, on the other hand, maternity leave legislation safeguards a woman's opportunity to return to her old job after taking leave, this may motivate higher investments in firm specific human capital and lead to higher seniority and better employer-employeematches. Hence, in spite of the labor supply effects and the passing on of benefit related costs to the women, the total effect of maternity leave on women's income could as well be positive. A potential wage increase may then again trigger an increased female labor supply and higher employment and re-entry rates. More women returning to work after taking leave will further decrease the recruiting and training costs for female employees (ONDRICH/ SPIESS/YANG 1996: 248). However, putting employers in the position of insurers may result in or reinforce a genderspecific labor market segregation because this may help in pooling risks and alleviate re-organization (JUNGWIRTH 1998: 85f). A gender-specific labor market segregation may again decrease women's wages by hampering direct 
competition of women for better paying "male jobs". As a consequence, the combined effect of maternity leave regulations on women's labor market position is ambiguous, even if the direct effect of some of the elements of maternity leave is to increase employment costs of female employees and will ceteris paribus lead to wage reductions and worsen the employment chances of women (BLAU/EHRENBERG 1997: 4; WALDFOGEL1998: 510, WALDFOGEL/ HIGUCHI/ABE 1999: 531). However, there are many other factors - as for example the availability of childcare for children of a certain age group, the social acceptability of young mothers working or the distribution of unpaid family and household work between men and women (PHIPPS/BURTON/LETHBRIDGE 2001) - that may influence the labor market position of young mothers.

\section{Maternity Leave Regulations in Different Countries: An Assessment of the Costs Imposed on Employers}

The US was not only "the last industrial country to establish an official program for maternity leave" (WINEGARRDEN/BRACY 1995: 1020), but they also have the shortest period of maternity leave among the countries under consideration. Even though the 1993 Family and Medical Leave Act (FMLA) provides for a 12 week absence from work (in a 12 months period), these 12 weeks include possible absences because of own health problems or that of close family members. Usually, the leave is taken all at once, but as an exception it can also be taken in parts (KOHLHAAS 1998: 2f). A short leave period should especially affect the costs of re-organizing in small firms for whom work-sharing agreements may not be feasible and who are bound to search for a substitute. Private firms with less than 50 employees, however, are exempted from the FMLA and do not have to provide maternity leave (O'CONNOR/ORLOFF/SHAVER 1999: 86). More than that, only employees that have been with their current employer for at least 12 months or for 1,250 hours, are covered by the FMLA. One further qualification alleviates the employer's re-organization problem of having to find an adequate short-term substitute for highly qualified workers: he may refuse to re-instate "highly compensated employees ... if .. such denial is necessary to prevent substantial and grievous economic injury to the operations of the employer" (ILR 136/1997: 124). As a result of these exemptions and qualifications, it is estimated that only $55 \%$ of employees and $19 \%$ of new mothers are in fact covered by the FMLA-provision (RUHM 1997: 177). There are, however, a number of Maternity Leave Statutes on state level (for an overview see KLERMAN/LEIBOWITZ 1997: 66), increasing the number of employees being covered by maternity leave provisions.

With a maternity leave duration of 14 weeks, the Law for the Protection of Mothers in Germany provides for a slightly longer period of leave. Unlike the US, however, this is granted in addition to sickness-related absences from work and there is a compulsory period of leave of 8 weeks. In effect, the duration of maternity leave will indeed be longer in Germany than it is in the US. This will in general make work-sharing arrangements more costly and the employment of substitutes more attractive. In face of specific skill requirements a 14-weeks leave period may, however, still be too short to allow for the replacement of the worker on leave, rendering (potentially costly) work-sharing arrangements the only practicable solution. Maternity leave in Denmark is slightly longer with 18 weeks (compulsory: 6 weeks), 14 of which are available after birth (ROSTGAARD/CHRISTOFFERSEN/WEISE 1999: 27).

Since the Employment Relations Act 1999, maternity leave in the $U K$ is granted for 18 weeks (ordinary maternity leave - OML), two of which are compulsory. Eligibility, however, is restricted to employees, such that other workers, e.g. those performing their job through an employment agency, are not covered. After one year of continuous service, leave-takers are further entitled to additional maternity leave (AML) up to the $29^{\text {th }}$ week after confinement. Again, this right only applies to employees. Furthermore, "there are circumstances ... where a failure to permit return will not be deemed automatically unfair dismissal" (e.g. when the employer has 5 or less employees and "it is not reasonably practicable to allow a return") (LEWIS 2000: 136f). As the woman is free to decide to start her OML from the $11^{\text {th }}$ week before expected confinement (SLADE 1999: 328), maternity leave may sum up to 40 weeks in total. When she returns, her job package, pay, seniority and pension rights have to be at least as favorable as when she left (BOWEIS/HONEYBULL 2000: 298f.). Whereas the 18-week OML-period would already seem to render work-sharing agreements problematic, a 40 -week leave period clearly seems to speak in favor of employing a substitute. Firms confronted with leave-takers in short supply will consequently suffer the most from these longterm leave provisions. 
Figure 2 displays the different maternity leave durations in the countries under consideration, where the shaded part of each bar marks the compulsory minimum period of absence, and the white part marks the maximum period of maternity leave women are entitled to take in case of single-pregnancy.

\section{Figure 2: Range between minimum and maximum maternity leave in different countries}

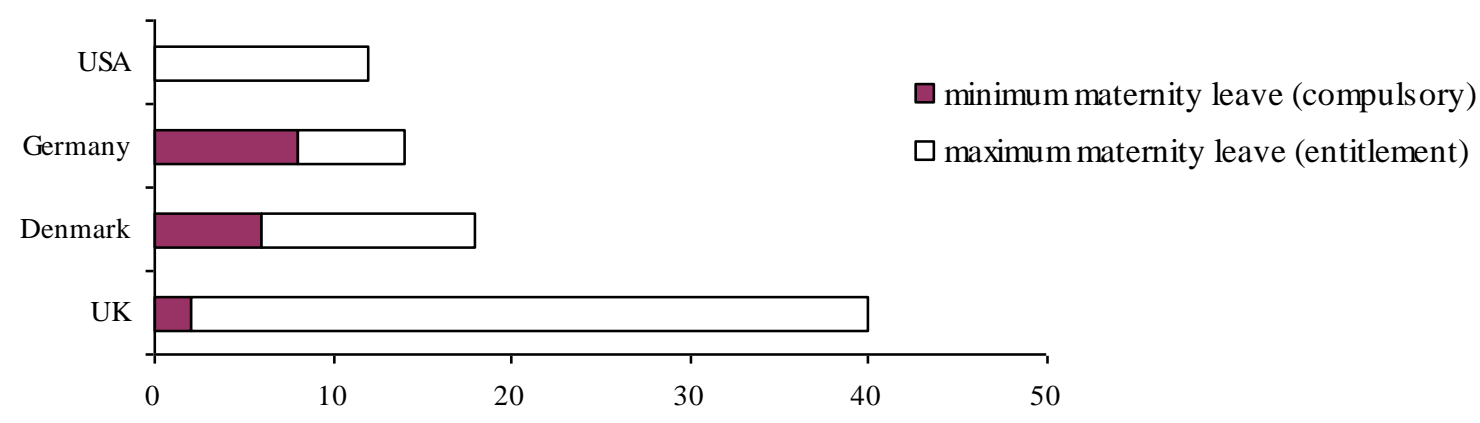

Turning next to the predictability of the leave duration (and hence including parental leave provisions), we find the following: Among the countries under consideration the US do not grant parental leave. The FMLA, however, is not restricted to maternity needs but covers a wide range of care needs and equally applies to women and men. Its potential to provide opportunities for child care is limited by its rather short duration of a maximum of 12 weeks per year to be taken by each parent and by the fact that it is restricted to the caring needs of a newborn, recently adopted or sick child. The short average duration of leave actually taken and the reasons given indeed reveal that "in practice it serves more as leave for family and medical reasons .. than as parental leave" (ILR 136/1997: 124; see also OECD 1995: 186). Concerning advance notice, the employer has the right to be informed of an intended family leave 30 days in advance (KOHLHAAS 1998: 2f.).

In Germany, according to the recently revised Federal Childcare Allowance Act, either parent may take parental leave up to the $3^{\text {rd }}$ birthday of the child. There are no service requirements. If the employer approves, one year of the parental leave provision can be postponed until the child's $8^{\text {th }}$ birthday. Young parents may also work parttime (up to 30 hours a week) while being on parental leave. The law leaves it to the parties of the employment contract to find a mutually agreeable part-time arrangement within 4 weeks. If they do not come to an agreement, the law prescribes a fallback position for workers that have been with their current employer for at least half a year and are employed in a firm with more than 15 employees: they have the right to shift to a part-time contract (15-30 hours a week) twice for a period of three months each - if there are no important obstacles from the part of the firm. In order to ease work re-organization, advance notice of part-time parental leave has to be given eight weeks ahead, and advance notice requirements for parental leave immediately following maternity leave have been increased from 4 to 6 weeks: 2 weeks after confinement the young mother has to decide on whether she wants to take advantage of parental leave provisions and must declare for which periods of time in the next two years she intends to be on parental leave. Returning early or remaining on leave for longer periods than initially declared demands the approval of the employer. (GOLA 2000: 36; HUNGENBERG 2000: 38f.). If the employee does not enter parental leave after the end of maternity leave and decides not to return to work at all she may terminate the employment contract without any notice requirement (SCHLACHTER 1999: 2368).

In Denmark, there is a basic family entitlement of 10 weeks of parental leave for parents of children up to 8 years old, which may be taken by either parent. The Act on Leave Schemes further entitles the parents to an additional uninterrupted period of childcare leave of another 13 weeks (26 weeks if the child is less than 1 year old or adopted) covering employees, self-employed workers, spouses assisting self-employed partners, unemployed and, in contrast to maternity leave, recipients of social assistance (ROSTGAARD/CHRISTOFFERSEN/WEISE 1999: 28; EOR 92/2000: 15). Furthermore, uninterrupted periods of leave of at least 13 and at most 52 weeks may also be agreed 
voluntarily with the employer. The total duration of all such leave must not exceed 52 weeks. The duration of leave counts towards the employee's continuous length of service. (JACOBSEN/HASSELBALCH 1999: 103.) The employee must make a written request to take up parental leave to the employer at least 4 weeks before the intended beginning of leave. If the duration of leave is not stated, the employee must give notice of return to work at least 8 weeks in advance. Employers may not refuse the request for parental leave, but they may postpone it for up to 26 weeks if they cannot find a substitute. (EIRR 262/1995).

In the $U K$, the Employment Relations Act (ERA) 1999 explicitly encourages employers and employees to agree on arrangements for parental leave that reflect their own particular needs. In case they do not come to an agreement, however, the Maternity and Parental Leave etc. Regulations 1999 specify a fallback scheme according to which qualifying employees are entitled to 13 weeks of parental leave for each child up to its $5^{\text {th }}$ birthday. The leave may be taken in blocks of one week or multiples of one week, up to a maximum of 4 weeks during any one year. An employer can make the provisions of the fallback or "default scheme" less favorable to the employees by way of a workforce or collective agreement (IDS 2000: 148). The employer further has the right to postpone a period of parental leave where work is of a seasonal nature, where a replacement cannot be found within the notice period [21 days], where a significant proportion of the workforce applies for parental leave at the same time or where a specific function is of strategic importance. Again, employer and employee are encouraged to agree on a mutually suitable time; if they don't succeed the employer has to guarantee that the employee can take the leave within the next 6 months at a time which bests fits the needs of the firm and of the employee. At the end of parental leave the employee has the right to return to the same or, if not possible, to an equivalent or similar job consistent with the employment contract. (IRLB 631/1999: 8f.). Concerning the relevance of the fallback scheme a recent survey on 50 work agreements (EOR 92/2000) reveals that the majority of organizations indeed apparently kept to the minimum requirement of 13 weeks leave; however, nearly half of them introduced more flexibility in terms of allowing longer periods of absence in any one year, $40 \%$ offered more generous notice periods. As for the right to return to the previous job after maternity leave, an employee must inform her employer at least 21 days before her absence that she will want to return afterwards and must indicate the expected week of confinement (SLADE 1999: 328). If she wishes to return right after OML, she then "simply presents herself for work"; if she wishes to return earlier than that, she must give notice at least 21 days in advance. In order for a woman to return to work after AML, there are no notice requirements. (BOWEIS 2000: 177f.) However, if the employer requests, the woman on leave has to give written confirmation of her intention to return to work, but not earlier than 21 days after the end of ordinary maternity leave. If the confirmation is not given within 14 days of receiving the request "or as soon thereafter as is reasonably practicable", the right to return to work will be lost. Provided she informed her employer about her intention to return to work, the employee has the right to return any time during additional maternity leave ( SLADE 1999: 328).

Summing up, in the US, which may be seen as being on one end of the spectrum, an employee can leave her workplace for a maximum of 12 weeks in response to pregnancy and childbirth and has to give notice 30 days in advance. In Germany, which is placed at the other end of the spectrum, an employee may leave for an initial period of 6 to 14 weeks and then decide to enter parental leave ( 6 weeks advance notice) postponing her decision to return to work for another 3 years or she may decide to not to return at all (no advance notice requirements). Denmark and the $U K$ are placed within this spectrum. The extent to which the legally provided potentially large variation in leave duration in Germany translates into a low predictability of leave duration (and as a consequence, into an aggravated labor market position of mothers in Germany as compared to mothers in the $U S$ ) is, however, an empirical question.

Concerning next the financing of maternity pay, in the US, employers are not obliged to pay wages during leave, but must continue health insurance benefits on the same terms as if the worker had not taken leave. No maternity pay as a wage replacement is stipulated by the FMLA. Consequently, the employer does not have to bear any wage related costs besides the continued health insurance. Women regularly do not get any wage replacement from other institutions either. In Germany, the main contractual obligations of both parties of the employment contract are suspended during maternity leave. Thus the employer does not have to continue payment. However, the law for the protection of mothers stipulates that the employer has to pay a "subsidy", which supplements a maternity payment by the health insurance (app. US\$ 10.50 or DM 25 per day) to the level of the woman's former net wages. The maternity payment by the health insurance and the employers' subsidy are not liable to social security contributions and to taxation. Depending on the gross and net income of the women, these stipulations result in varying financing cost 
shares of the state, the social insurance and the employer. For a typical female worker in firms with more than 20 employees who earns a gross income of app. US\$ 1,841 (DM 4,000), the employer's share is about 35 per cent of the gross payroll cost of app. US\$2,209 (DM 4,800) and about 40 per cent of the gross monthly wages, while the social insurance institutions bear approximately 50 per cent and the state the remaining 15 per cent of gross payroll cost (ALEWELL 2000). For firms with 20 or less employees there is a compulsory insurance for maternity pay. Premiums are calculated as a percentage of total payroll cost irrespective of the number of female employees. In Denmark, women receive weekly payments during the maternity leave of 4 weeks before expected confinement and of 14 weeks after the confinement. Fathers may receive weekly payments for 2 weeks within the 14 weeks following birth and for 2 weeks after expiry of the 24 weeks period. The maternity cash benefit is calculated on the basis of the hourly wage of the worker and the number of hours worked, with a maximum of app. US\$ 344 per week (DKK 2,846 ), which is paid by social insurance institutions. However, there are several collective agreements which provide for the continued payment of 100 per cent of wages and salaries for certain groups of employees. In this case, employers are entitled to receive the maternity cash benefit paid by the social insurance institutions. Benefits are fully liable to taxation and contributions to the supplementary pension scheme have to be paid out of the benefits (MISSOC ONLINE 2001). In the $U K$, pregnant working women or young mothers are entitled to receive either statutory maternity pay (SMP) from their employer or maternity allowance (MA) from the Department of Social Security if they cannot get SMP. Both SMP and MA are payable up to 18 weeks and are only payable in weeks in which the recipient doesn't work. SMP is paid at $90 \%$ of the woman's average weekly earnings for the first 6 weeks and app. US\$ 88 ( $£ 60.20$; updated yearly in April) for the remaining 12 weeks. The amount is equivalent to approximately $1 / 3$ of the average weekly wage for women (DTI 2000: 10). It is payable if the woman has been employed continuously by her employer since the very beginning of her pregnancy and if she earns at least app. US\$97 (£ 67) a week on average. The state reimburses employers for 92 per cent of the SMP they have paid out (or 105 per cent if their national insurance liability in the previous tax year was US\$29,100 ( $£ 20,000$ ) or less). In order to qualify for MA a woman must have been employed or registered as self-employed for at least 26 weeks during the last 15 months before confinement. She must also earn at least app. US\$ 44 ( $£ 30)$ a week on average. MA is paid at app. US\$ 88 ( $£ 60.20$ ) a week or 90 per cent of the woman's average earnings if she earns less than US\$98 ( $£ 67$ ) a week (DTI 2000, MISSOC ONLINE 2001).

Comparing the employers' burden related to maternity pay in the different countries, we construct a common scale by calculating the number of weeks for which the employer has to pay full wages even though the woman is on leave and does not work. For example, if the employer has to pay 50\% of the normal weekly wages for a woman on leave for 14 weeks, we express this as the payment of full weekly wages for 7 weeks. We only look at payments which are due by virtue of federal laws and valid for the whole country and all employees under consideration, because collective agreements and state laws differ within countries and there are special stipulations for certain groups of employees. If the women may choose the length of maternity leave and can thus influence the amount of maternity pay, or if there are different regulations for different types of employers, we base our calculation on the maximum amount an employer may have to pay. In the $U S$, there is no maternity pay as far as federal law is concerned. Thus, the employer doesn't have to pay any wage replacement, but has to continue health insurance benefits which vary between employers and employees and are therefore not covered by our common scale. Hence, we get zero full weekly wages as the employers' share in maternity pay. In Denmark, employers don't bear any costs either, as maternity pay is provided by the social insurance institutions. Thus we get the same result as for the US: zero full weekly wages. In the $U K$, SMP is paid at $90 \%$ of the normal weekly wage for 6 weeks and at one third of the average weekly wage of women for a maximum of 12 following weeks. The employer is reimbursed for a minimum of $92 \%$ of these payments. Thus we get 0.75 full weekly wages as average employer share (6 weeks times $90 \%$ plus one third of average wages for 12 weeks resulting in 9,4 weeks of full payment of which the employer bears up to $8 \%$.) In Germany, the employer has to pay a subsidy which supplements the payment by the health insurance up to the level of the former net income of the women for 14 weeks. The subsidy equals approximately $40 \%$ of a typical woman's wage. Hence we get 5.6 full weekly wages as the employers' burden from maternity pay. Table 1 summarizes the financial burden placed on the employer by making him contribute to the financing of maternity pay.

Table 1: The employers' financial burden from maternity pay in the countries under consideration 


\begin{tabular}{|l|c|}
\hline Country & Full weekly wage payments borne by the employer during maternity leave \\
\hline US & $0.00^{\mathrm{a}}$ \\
\hline Germany & $5.60^{\mathrm{b}}$ \\
\hline Denmark & $0.00^{\mathrm{c}}$ \\
\hline UK & $0.75^{\mathrm{d}}$ \\
\hline
\end{tabular}

a. $\quad$ Plus continued health insurance premiums. State Laws may provide for different regulations.

b. Calculated for a typical women who has a gross wage per month of DM 4,000.

c. Collective Agreements provide for many different regulations.

d. Smaller employers bear less because their reimbursement percentage is higher.

Concerning the isolated effects of the employers' burden from maternity pay, in Germany, wage and employment differentials between men and women can be expected to be larger, while wage and employment differentials in the U.S. and Denmark can be expected to be smaller. We expect the stipulations in the $U K$ to have negative effects on the labor market position of young women, too. Here the administrative costs of having to first pay out the wages and then being reimbursed by the state, further add to the direct costs of having to finance part of the SMP.

Summing up our argument, we get clear cut results for some of the countries under consideration (table 3): The US have a very short duration of maternity leave, a high predictability of total leave duration related to childbirth and put only a small financial burden on employers concerning maternity pay. Consequently, the problems maternity leave regulations may cause for the employer will be rather small and negative effects on the labor market position of women will only be minor. Denmark has an intermediate duration of maternity leave which may be especially costly to employers, predictability, too, is only at an intermediate level. In the U.K., the large span of possible durations of the leave combined with a low predictability of total leave duration and the co-financing of maternity pay by employers may aggravate the labor market position of young women. However, the very short compulsory minimum duration and the comparatively long maximum duration of maternity leave could alleviate cost minimizing re-organization solutions if women were to decide for one of the extremes, which, again, is an empirical question. Germany is, from the viewpoint of employers, to be found at the most costly end of the spectrum: An intermediate and potentially especially costly duration of maternity leave, a potentially high variation in total leave duration related to childbirth, and the highest employer share in maternity pay all contribute to this result.

Table 3: Maternity Leave Duration, Predictability of Total Leave Duration and the Financing of Maternity Pay

\begin{tabular}{|l|c|c|c|}
\hline Country & $\begin{array}{c}\text { Minimum/Maximum Duration } \\
\text { of Maternity Leave }\end{array}$ & $\begin{array}{c}\text { Degree of Predictability of Total } \\
\text { Leave Duration }^{\mathbf{a}}\end{array}$ & $\begin{array}{c}\text { Employers' Share in Maternity } \\
\text { Pay (full weekly payments) }^{\mathbf{b}}\end{array}$ \\
\hline US & 0 weeks/12 weeks & Very high & 0.00 \\
Germany & 8 weeks/14 weeks & Low & 5.6 \\
Denmark & 6 weeks/18 weeks & Intermediate & 0.00 \\
UK & 2 weeks $/ 40$ weeks & Low to Intermediate & 0.75 \\
\hline
\end{tabular}

a. Total Leave Duration from maternity and parental leave; unpredictability stems from high number and broad scope of decisions the women may make during leave as well as short notification periods.

b. Employers' Share as stipulated in legal regulations; calculations based on maximum possible share.

If we take a look at employment levels and relative wages of women in the countries under consideration (table 4), it becomes obvious that employment levels and relative wages of women in Germany indeed are lowest Germany representing the country with the potentially largest cost burden for employers. This comparison of employment levels and relative wages being illustrative at its best, we proceed by presenting existing empirical studies on the effects of maternity leave provisions on the employers' re-organization problem, on the women's decision to work and - last but not least - on the labor market position of young women as a function of maternity leave provisions. 
Table 4: Employment and Wages of Women in the Different Countries

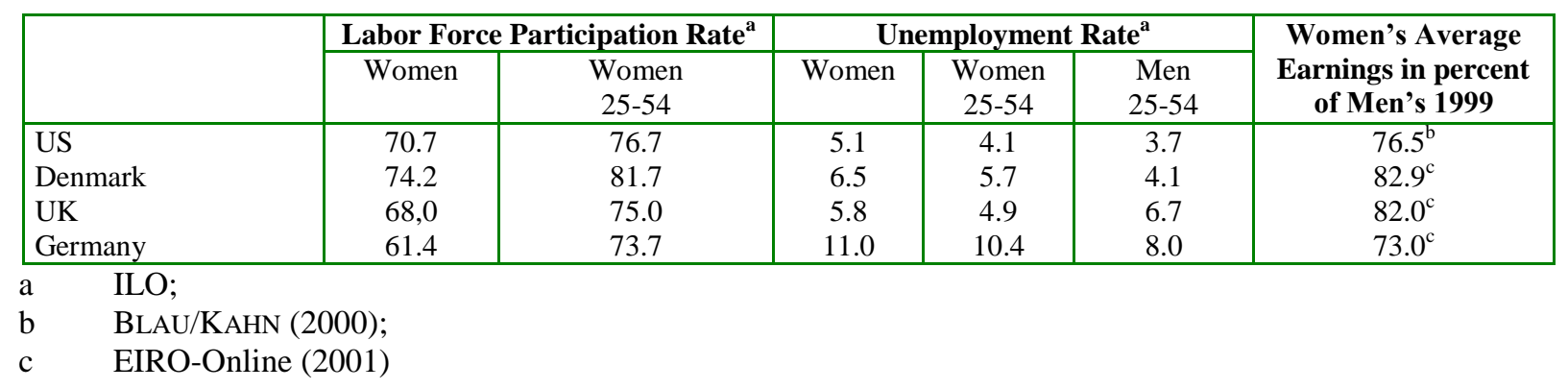

\section{Empirical Studies on Maternity Leave}

Asked for problems of re-organizing work as a consequence of maternity leave, employers regularly state only minor difficulties (OECD 1995: 190). Consistent with our theoretical analysis, major problems with maternity leave provisions seem to concern only the small employers and those confronted with high-skill leave-takers in short supply. While the first can be expected to have problems finding work-sharing agreements (there might be no colleagues in the same job) the latter obviously will have a hard time replacing the leave takers. If sharing arrangements are out of reach, small firms are effectively bound to employ a substitute (which is especially costly in case of a short period of maternity leave); if the replacement of a leave taker is unfeasible, employers are effectively bound to search for a work-sharing arrangement (which is especially costly in case of a long period of maternity leave). Also for parental leave, it is the small firms and those having to replace workers in short supply, that report problems (CORE/KOUTSOGEORGOPOULOU 1995: 18). All of these observations are perfectly in line with our theoretical considerations. If job tenure is taken to be a proxy of the amount of specific human capital acquired, the findings by SoFRES (1993) would further seem to underline our suppositions on the importance of firm-specific human capital in deciding on the employment of a substitute vs. searching for a work-sharing arrangement: In his empirical study for France, 86 per cent of employees on leave who had been with their current firm for less than 2 years were substituted for the time of leave, whereas the figure for those employees who worked for more than 15 years in the same firm (and arguably had acquired a significant amount of specific human capital by that time) was only 57 per cent (OECD 1995: 190). The plausibility of our argument is strengthened, too, by the study by NäSMAN (1991, cited by OECD (1995: 190) for the Swedish context (14 week compulsory maternity leave) where employers have argued for longer periods of absence. This is compatible with the proposed hump-shaped curve displaying the costs of re-organization as a function of the duration of maternity leave: While a 14-week leave period may already be too long for a work sharing arrangement to be feasible, it may still be too short a time to hire and train a substitute for the employee on leave.

As far as empirical evidence on the costs of parental leave accruing to the employers is concerned, there are but a few empirical studies - again hinting at these costs not being too high (e.g. SCHIERSMANN 1996: 54ff): According to a 1991-study, between 1985 and 1988 only 1.1 per cent of employees in Germany were on maternity or parental leave. Hence, already by the numbers, re-organizing during maternity and parental leave may only be of minor importance. According to the study the predominant way of re-organizing work during parental leave was the replacement of the leave-taker (in face of the long-term character of parental leave this would seem to be in line with our theoretical arguments). While major employers were often able to recruit the replacement staff internally, small employers were more dependent on the external labor market and also tried to increase the working hours of the remaining employees (particularly part-timers). Again this would seem to be in line with our theoretical arguments. The fact that take-up rates for parental leave are generally lower for employees in executive positions (see e.g. SCHIERSMANN 1996: 52; CORE/KOUTSOGEORGOPOULOU 1995: 17) should further alleviate the employers' re-organization problem in case of parental leave. In the literature it has even been argued that the absence of parental leave provisions could well be more costly for employers than a "well-planned" parental leave policy (ILR 136/1997: 123). Employer provided parental leave (see e.g. DEN DULK 1999) could be an indication of that. Not only may absenteeism in fact be higher without parental leave arrangements and time at work less productive, but the risk of per- 
manently losing a qualified worker may be higher entailing heavy costs for the employer. The chance to hold on to a valued employee, however, would seem to depend on the young mother's decision to actually return to work following maternity and/or parental leave.

How long young mothers are actually absent from work on top of compulsory maternity leave in the different countries, is an empirical question. While short provisions of maternity leave may induce women to quit the workplace altogether and only return after years (i.e. result in rather long periods of absence and at times even a complete loss of employer-financed investments in firm-specific human capital), intermediate provisions may result in shorter periods of absence as compared to a situation without maternity leave: Without maternity leave provisions a young mother may decide to quit the job and only return after years; with maternity leave provisions the same woman may decide to return right after the end of the provision in order to keep her job. The set of alternatives a young mother faces may actually be changed in a way such that the provision of maternity leave effectively shortens the period of absence. The results by RONSON/SUNDSTROM (1996: 283f.) for Sweden and Norway are illustrative in this respect: "In both countries, women who have the right to a paid leave are much more likely to resume employment, and they do so almost three times as fast as other women in Sweden and more than twice as fast in Norway.... Generally, it seems that a longer entitlement period such as the Swedish one in the 1980's will enable more mothers to re-enter before the leave expires, resulting in higher overall re-entry rates. With shorter entitlements, as in Norway, a few women will return more quickly, but a larger number will end up outside the labor force because it is more difficult to reconcile work and motherhood when the baby is very young."

But obviously, it is not only the length of maternity leave provided that determines a woman's decision to return to work and when to return to work. According to a study by MCRAE (1991: xxxix) for the $U K$, a young mother's decision to return to the job is a function of her hourly pay, her educational qualifications, the provision of maternity pay, the type of employer (public vs. private) and the number of children. In an empirical study of about 250 dual earner households in the UK undertaken by BRANNEN/MOSS (1991) about 50\% of young mothers returned to work after maternity leave ( $42 \%$ full-time, $9 \%$ part-time). The availability of parental leave obviously also plays a role: In Germany in 1996, the take-up rate of parental leave following maternity leave was 96\%, i.e. in almost every case women did not return to their jobs at the end of maternity leave (fathers in parental leave only play a minor role in Germany representing an estimated 1-2\% of parental-leave takers) (BRUNING/PLANTENGA 1999: 200). For one, this alleviates the employer's uncertainty about the duration of leave: He can be almost certain that his female employee will not return to work after her 8-14 week maternity leave. As a consequence, the uncertainty about absence duration may not be as high as the legal stipulations at first would have suggested. In Denmark, however, the takeup rate for young mothers in 1995/6 was 33\% (3\% for men) (BRUNING/PLANTENGA 1999: 200), potentially creating much more uncertainty on the part of employers about whether their (female) employees will in fact take parental leave or not. Among the factors explaining the observed international differences in take-up rates, the question of compensation during parental leave and the availability of child care seemingly are the most important (CORE/KOUTSOGEORGOPOULOU 1995: 17), but different traditions in female labor force participation and the social acceptability of working mothers may even nowadays still play a role (SCHIERSMANN 1996: 52). The fact that in Germany in 1989/90, public childcare for children under 3 years of age was available for only 3\% of children (SCHIERSMANN 1996: 46) combined with the "widespread belief in Germany that children in their first three years of life ... should be cared for by their own mothers" (PETTINGER 1999: 134), may well explain the high take-up rates of parental leave. Providing for parental leave, however, does not mean that a young mother will return to work afterwards. Reconciling family and work life may still be too difficult a task: Even though in a recent study, mothers were the main earners in $40 \%$ of respondents' households, they were "the chief carers on every indicator assessed. For example, more than two-thirds of mothers (68\%) say they are usually called first if their child is ill, compared with 13\% of men" (EOR 93/2000a: 3). Anticipating that the wide-spread perception of the "having it all"-workingmothers is no more than a "myth" (EOR 93/2000b: 4), a young mother may well decide not to return to work following maternity and/or parental leave. In Germany indeed only half of young mothers on parental leave return to work afterwards (CORE/KOUTSOGEORGOPOULOU 1995: 17). Again, this may be due to a lack of public childcare in Germany, where public childcare for children aged 3 to 6 is typically part-time and where the length of the school day in primary school is 4-5 hours (SCHIERSMANN 1996: 46). Another reason for the low rate of returns of German mothers may be the rather long leave duration: According to a study by RONSEN (1999) women who are entitled to paid leave take up employment faster than non-entitled women, but the difference between the two groups vanishes 
for long periods of leave, such that for German mothers it may take long again to return to work.

Hence, trying to assess the costs of maternity and parental leave resulting from the different regulations concerning its length and method of financing, does not seem to be an easy task as the costs accruing to the employer are not only a function of the legal regulations in place, but also a function of the availability of child care that may indeed substantially affect a young mother's decision to return to work after maternity or parental leave (see also ESCOBIDO 1999 on the interplay between parental leave and the availability of child care). However, comparing the situation in different countries still shows some clear cut differences: Whereas an employer faced with a pregnant employee in Germany will not only have to co-finance maternity pay, but with almost certainty (96 per cent) he will also have to encounter a 3-year-leave period and still faces a considerable risk of permanently losing the employee afterwards (50 per cent), an employer in the US is confronted with a maximum leave duration of 12 weeks per year and will then know for sure if his employee will return or not. According to BLANK (1999: 179) in the US in 1994 only 44.5 per cent of young mothers with a child between 2 and 4 years of age were not in the labor force, a rather low figure compared to international standards (e.g. for the Netherlands the figure was 73.2 per cent), hinting at non-negligible rates of return.

To date, there have been a couple of empirical studies trying to assess the effects of maternity and parental leave provisions on the labor market position of young women. Concerning the effects on employment, RUHM (1998: 286f.) estimates that the overall effect of maternity and parental leave in the 9 European countries under consideration was an increase in women's labor market participation of 4 per cent and more in the relevant age groups. ONDRICH/SPIESS/YANG (1996: 248) summarize empirical studies for the US and conclude that (the coverage with) leave regulations increases the labor market participation of women. These results are confirmed by other studies for the US (WALDFOGEL 1998, WINEGARDEN/BRACEY 1995) as well as in a comparative analysis of the US, Japan and the UK (WALDFOGEL/HiguCHI/ABE 1999: 541). Concerning the effect of leave duration on remuneration, in his analysis of 9 European countries including Denmark and Germany, RUHM (1998) indeed finds that maternity and parental leave provisions of up to 12 weeks result in wage reductions for female employees of up to 1 per cent, while longer leave periods of up to 40 weeks result in income losses of up to 4 per cent. His review of existing studies, however, reveals mixed and ambiguous effects of leave duration on remuneration, which could well be the result of a non-linear relationship between leave duration and the costs of re-organization accruing to the employer. It may also be the result of his failing to include the direct costs of employers having to contribute to the financing of maternity pay. MiTCHELL (1990: 309) e.g. finds that the costs of mandated benefits which are borne by employers indeed are partially shifted on to the relevant groups of employees in the form of lower wages. And also GRUBER (1994: 622, 639) argues that in the US health insurance which is partially employer-financed, the mandated inclusion of pregnancy and motherhood related health risks resulted in wage reductions for female employees. Taking into account the different demand and supply effects of maternity leave provisions, WALDFOGEL (1997: 122; 1998: 534) who analyzes gender specific wage differentials in the $U S$ and in the $U K$ comes to the conclusion that expanding maternity leave provisions would indeed decrease wage differentials. In the same line, DEX/JOSHI/MACRAN (1996) infer from their empirical study of the $U K$, that widening the scope of maternity leave regulations would improve women's labor market situation, and JOSHI/PACI/WALDFOGEL (1999) conclude that the introduction of statutory maternity leave in the $U K$ helped women to forego career interruptions and decrease the wage gap relative to non-mothers and men by maintaining continuous employment histories. WALDFOGEL (1995) shows, again with data from the $U K$, that from the women's perspective the coverage with maternity leave makes up for the wage penalty associated with having one child and more than half of the negative wage effect associated with having two or more children. PHIPPS/BURTON/LETHBRIDGE (2001) test the hypothesis that human capital depreciation due to childrelated work interruptions on the one hand and higher levels of women's unpaid, family and household related work together explain the wage gap between Canadian women with and without children and conclude that the two hypotheses together can reduce, but not eliminate the unexplained wage gap.

\section{Conclusions}

Maternity Leave Regulations are currently being revised in many countries around the world (e.g. in Japan, Switzerland and in the $U K$ ). Policy makers consider changes in maternity leave regulations seeking to improve the compatibility of work and family life and the labor market position of women at the same time. Our analysis shows 
that these two aims do not necessarily have to contradict each other. Firstly, it is not unambiguously true that a long maternity leave causes the biggest problems for employers, but for many firms an intermediate duration of maternity leave will be especially costly and may have the largest negative impact on women's labor market position, because it renders work-sharing-solutions inefficient without allowing for substitution solutions. Secondly, what is especially problematic for employers is the uncertainty about total leave duration associated with childbirth, as unpredictability presents one major obstacle in reaching the cost minimizing re-organizing solution. Hence, it may well be possible to improve the labor market position of women via alleviating the problems of re-organization by increasing the predictability of total leave duration. This would, for example, imply to reduce the number of decisions and to narrow the span of possible decision outcomes the women may take without the consent of the employer, while the duration of maternity leave does not necessarily have to be shortened. At first sight worsening the situation for working mothers, this measure may well improve their labor market situation in the middle or long run. On the other hand, policy makers who currently think about increasing the length of maternity leave, as in the UK (DTI 2000) or Japan, should take care not to simultaneously decrease the predictability of leave duration in order to safeguard women's labor market position in the long run. However, legal stipulations are only one factor in determining the re-entry decision of women, social acceptability of young mothers working and the availability and attractiveness of child care arrangements being other potentially important determinants. Thirdly, some countries, like Germany, and to a much lesser extent, the $U K$, still burden employers with the (partial) financing of maternity pay. They could alleviate the costs of maternity leave for employers, decrease female-male-wage differentials, and thus improve the labor market situation of young women by looking for other ways of financing maternity pay.

\section{References}

1. Alewell, D. (2000): Ökonomische Analyse der Regelungen des Mutterschutzes; in: Zeitschrift für Personalforschung, Vol. 14, No. 4, 312-333

2. $\quad$ Blau, D.F./Ehrenberg, R.G. (1997): Introduction; in: Blau, F.D./Ehrenberg, R.G. (eds.): Gender and Family Issues in the Workplace, New York, 1-19.

3. Blau, F.D./Kahn, L.M. (2000): Gender Differences in Pay; in: Journal of Economic Perspectives, Vol. 14, 75-99

4. $\quad$ Boweis, J. (2000): Employment Law, $5^{\text {th }}$ edition. London.

5. Boweis, J. /Honeyball, S. (2000): Labour Law, $5^{\text {th }}$ edition, London.

6. Brannen, J. /Moss, P. (1991): Managing Mothers: Dual Earner Households After Maternity Leave. London.

7. Bruning, G./Plantenga, J. (1999): Parental Leave and Equal Opportunities: Experiences in Eight European Countries; in: Journal of European Social Policy, Vol. 9, 195-209.

8. Coré, F./Koutsogeorgopoulou, V. (1995): Parental Leave: What and Where?; In: The OECD Observer, 195/1995: $15-20$

9. Den Dulk, L. (1999): Employers and parental leave: a comparative analysis; In: Moss, P. /Deven, F. (eds.): Parental Leave: Progress or Pitfall? Brussels: 227-247.

10. Dex, S./Joshi, H./Macran, S. (1996): A widening gulf among Britain's mothers; in: Oxford Review of Economic Policy; Vol. 12, No. 1, 65-75.

11. DTI (Department of Trade and Industry) (2000): Work and Parents: Competitiveness and Choice; London.

12. EIRO Online (2001): Gender Perspectives - annual update 2000; http://www.eiro/eurofound.ie/2001/03/updates/ tn0103201u.html

13. EIRR (European Industrial Relations Review) (262/1995) Parental Leave in Europe. 14-23

14. EOR (Equal Opportunities Review) (92/2000): Parental Leave in the U.K. 12-18.

15. EOR (Equal Opportunities Review)(93/2000a): Better maternity rights damage women's prospects. 3-4.

16. EOR (Equal Opportunities Review)(93/2000b): Working mothers under most pressure. 4.

17. Escobido, A. (1999): Doing cross-national work on parental leave; in: Moss, P. /Deven, F. (eds.): Parental Leave: Progress or Pitfall? Brussels: 173-192.

18. Gola; P. (2000): Vertragsfreiheit und Teilzeitbeschäftigung - neue Rechtsansprüche auf Teilzeitarbeit; In: Lohn und Gehalt 8/2000: 35-37.

19. Gruber, J. (1994): The Incidence of Mandated Maternity Benefits; in: American Economic Review, Vol. 84, $622-641$.

20. Hungenberg, H. (2000): Änderung des Bundeserziehungsgeldgesetzes; in: Lohn und Gehalt 8/2000: 38-39. 
21. IDS (Incomes Data Services) (2000): Maternity and Parental Rights: Employment Law Handbook London.

22. ILR (136/1997): Perspectives: Parental Leave, 109-128.

23. IRLB (631/1999): Maternity and parental leave, 4-12.

24. Jacobsen, P./Hasselbach, O. (1998): Denmark In: Blanpain, R. (ed.): International Encyclopedia for Labor Law and Industrial Relations, Vol. 5.

25. Joshi, H./Paci, P./Waldfogel, J. (1999): The wages of motherhood: better or worse?; in: Cambridge Journal of Economics, Vol. 23, 543-564.

26. Jungwirth, C. (1998): Berufliche Ein- und Aufstiegschancen von Frauen - Förderwirkung und Barrieren durch MuSchG und BerzGG; Wiesbaden.

27. Klerman, J.A./Leibowitz, A. (1997): Labor Supply Effects of State Maternity Leave Legislation In: Blau, F.D./Ehrenberg, R.G. (eds.): Gender and family issues in the workplace. New York: Russell Sage: 65-85.

28. Kohlhaas, S. (1998): Das Arbeitsrecht in den USA. German Chamber of Commerce. New York.

29. Lewis, P. (2000): Pregnancy and maternity leave: employment law as a family friend? In: Industrial Relations Journal Vol. 31, 130-143.

30. McRae, S. (1991): Maternity Rights in Britain: the experience of women and employers; in: Policy Studies Institute; London.

31. Missoc Online (2001): Online Information System about legislation in the EU member states, http://europa.eu.int/comm/employment_social/missoc2000/missoc_87_en.htm.

32. Mitchell, O.S. (1990): The Effects of Mandating Benefit Packages. In: Bassi, L./Crawford, D. /Ehrenberg, R. (eds.), Research in Labor Economics 11, 297-320.

33. O'Connor, J./Orloff, S./Shaver, S. (1999): States, Markets and Families: Gender, liberalism and Social Policy in Australia, Canada, Great Britain and the US; Cambridge, New York, Melbourne.

34. OECD (1995): Long-term leave for parents in OECD countries In: Employment Outlook 1995: 171-202.

35. Ondrich, J.C./Spiess, K./Yang, Q. (1996): Barefoot and in a German Kitchen: Federal Parental Leave and Benefit Policy and the Return to Work after Childbirth in Germany. In: Journal of Population Economics 9, 247-266.

36. Pettinger, R. (1999): Parental Leave in Germany; In: Moss, P./Deven, F. (eds.): Parental Leave: Progress or Pitfall?; Brussels: 123-140.

37. Phipps, S. /Burton, P./Lethbridge, L. (2001): In and Out of the Labor Market: long-term income consequences of child-related interruptions to women's paid work; in: Canadian Journal of Economics, Vol. 34, No. 2, 411-429.

38. Ronsen, M. /Sundstrom, M. (1996): Maternal Employment in Scandinavia: A Comparison of the AfterBirth-Employment Activity of Norwegian and Swedish Women; in: Journal of Population Economics, Vol. 9, No. 3, 267-285.

39. Ronsen, M. (1999): Assessing the impact of parental leave: effects on fertility and female employment; In: Moss, P./Deven, F. (eds.): Parental Leave: Progress or Pitfall?; Brussels: 193-225.

40. Rost, H. (1999): Fathers and Parental Leave in Germany; In: Moss, P./Deven, F. (eds.): Parental Leave: Progress or Pitfall?: Brussels: 249-266.

41. Rostgaard, T./Christoffersen, M.N./Weise, H. (1999): Parental Leave in Denmark; In: Moss, P./Deven, F. (eds.): Parental Leave: Progress or Pitfall?; Brussels: 25-44.

42. Ruhm, C.J. (1997): Policy Watch. The Family and Medical Leave Act; in: Journal of Economic Perspectives 11, 175-186.

43. Ruhm, C.J. (1998): The Economic Consequences of Parental Leave Mandates: Lessons from Europe; in: Quarterly Journal of Economics, 285-317.

44. Ruhm, C.J./Teague, J.L. (1997): Parental Leave Policies in Europe and North America; in: Blau, F.D./Ehrenberg, R.G. (eds.): Gender and Family Issues in the Workplace. New York: Russell Sage: 133156.

45. Schiersmann, Ch. (1996): A comparison of the conditions for reconciling professional and family life in Europe - with special consideration or regulations governing parental leave; in Transfer 1/1996, 36-60.

46. Schlachter, M. (1999): Kommentar zum Mutterschutzgesetz; in: Erfurter Kommentar zum Arbeitsrecht, München, 2348-2382.

47. Slade, E. (1999): Tolley' Employment Handbook 13. Auflage. Croydon.

48. Summers, L.H. (1989): What can economics contribute to social policy? Some simple economics of man- 
dated benefits. In: American Economic Review 79, Papers and Proceedings, 177-183.

49. Waldfogel, J. (1993): Women working for less: A Longitudinal Analysis of the Family Gap; Working Paper WSP/93, London School of Economics Suntory-Toyota International Centre for Economics and Related Disciplines.

50. Waldfogel, J. (1995): The Price of Motherhood: Family Status and Women's Pay in a Young British Cohort; in: Oxford Economic Papers, Volume 47, No 4, 584-610.

51. Waldfogel, J. (1997): Working mothers now and then: a Cross Cohort Analyses of the Effects of maternity Leave on Women's Pay; in: Blau, F.D./Ehrenberg, R.G. (eds.): Gender and Family Issues in the Workplace, New York, 1997, 92-126.

52. Waldfogel, J. (1998): The family gap for young women in the US and Britain: Can Maternity Leave Make a Difference? In: Journal of Labor Economics 16, 505-545.

53. Waldfogel, J. /Higuchi, Y./Abe, M.(1999): Family leave policies and women's retention after childbirth: Evidence from the US, Britain, and Japan; in: Journal of Populations Economics, Vol. 12, 523-545.

54. Winegarden, C.R./Bracy, P. M. (1995): Demographic Consequences of Maternity-Leave Programs in Industrial Countries: Evidence from Fixed-Effects Models; in: Southern Economic Journal 6(1995): 10201035 . 